Int. J. Electrochem. Sci., 15 (2020) $915-928$

International Journal of

ELECTROCHEMICAL

SCIENCE

WWW.electrochemsci.org

\title{
A silicomolybdate/graphene/poly(3,4-Ethylenedioxythiophene) Composite Film as a Sensor for Sensitive Determination of Persulfate
}

Weihua Guo ${ }^{1,2, *}$, Jianguo $\mathrm{Ma}^{2}$, Xiaohong $\mathrm{Cao}^{2}$, Xiaolan Tong ${ }^{2}$, Fen Liu ${ }^{2}$, Yunhai Liu ${ }^{2, *}$

${ }^{1}$ State Key Laboratory of Nuclear Resources and Environment, East China University of Technology, Nanchang, 330013, Jiangxi, China

${ }^{2}$ Chemistry, Biological and Materials Sciences Department, East China University of Technology, Nanchang, 330013, Jiangxi, China

*E-mail: guowh0604@163.com, whguo@ecit.cn, walton_liu@163.com

doi: $10.20964 / 2020.01 .84$

Received: 29 September 2019 / Accepted: 21 November 2019 / Published: 30 November 2019

A poly(3,4-ethylenedioxythiophene)-electrochemically reduced graphene oxide (pEDOT-ERGO) composite film was synthesized by one-step electropolymerization approach on the Indium tin oxide (ITO). The composite was further decorated with $\mathrm{H}_{4} \mathrm{SiMo}_{12} \mathrm{O}_{40}$ (SiMo12) by electrochemical growth method and applied as an electrode material for the detection of persulfate. pEDOT acted as a bridge in the composite because it is positively charged and can interact with the negatively charged species. Data from scanning electron microscopy (SEM), energy dispersive spectroscopy (EDS) and cyclic voltammetry demonstrated that the SiMo12/pEDOT-ERGO film was successfully synthesized. The electrode surface has a granular-like protrusions structure and a large specific surface area. As a result of the catalytic activity of SiMo12 and the good conductivity of pEDOT-ERGO, the modified electrode displays better electrocatalytic activity toward the reduction of persulfate. The sensor has a linear response in the $1.5-132 \mu \mathrm{M}$ range with a detection limit $(0.48 \mu \mathrm{M})$, better sensitivity $\left(0.22 \mu \mathrm{A}_{\mu} \mathrm{M}^{-1} \mathrm{~cm}^{-}\right.$

2 ), favorable anti-interference and good stability.

Keywords: Graphene oxide, Polyoxometaltes, Poly(3,4-ethylenedioxythiophene), Persulfate, Electrocatalysis, Modified electrode

\section{$\underline{\text { FULL TEXT }}$}

(C) 2020 The Authors. Published by ESG (www.electrochemsci.org). This article is an open access article distributed under the terms and conditions of the Creative Commons Attribution license (http://creativecommons.org/licenses/by/4.0/). 